\title{
The Monitoring of Rare Earths Mining from the Gannan Area of Southern China Using Remote Sensing Technology
}

\author{
Baoying $\mathrm{Ye}^{1}$, Zhenghui Chen ${ }^{2}$, Nisha $\mathrm{Bao}^{3}$, and Ying $\mathrm{Li}^{4}$ \\ ${ }^{1}$ Institute of the Geology Survey, China University of Geosciences, Beijing, China \\ ${ }^{2}$ Institute Mineral Resources, Chinese Academy of Geological Sciences, Beijing, China \\ ${ }^{3}$ Institute for Geo-informatics \& Digital Mine Research, \\ Northeast University, Shenyang, China \\ ${ }^{4}$ Tianjin Institute of Geology and Mineral Resources, Tianjin, China \\ yeebaoying@gmail.com
}

\begin{abstract}
The weathering crust Elution-deposited Rare Earth is the peculiar and valuable source in China. The greatly mining activities in the south of GanZhou(Gannan) were occurred disorderly and illegally using the traditional extraction way, which brought out the dreadful environmental influence. In this study, the SPOT5 multi-spectral data was used to recognize and classify the destroyed land from mining activity. It was found that the most mining areas were located dispersedly, covered the area of $60.97 \mathrm{~km} 2$ in total with 524 sites, which accounted for $3.03 \%$ of the whole study area. There were 513 patches of destroyed area less than $1 \mathrm{~km} 2$ distributed in the southwest of the study area. The results indicated that the mining integration should be concerned in this region and mining plan for further environmental protection.
\end{abstract}

Keywords: South of Ganzhou, Rare earth, Remote sense, Monitoring.

\section{Introduction}

Remote sensing and GIS technology play a key role in the study of Land use/cover change [1].There were many researches focused on the environmental change from mining area using remote sensing data. These studies showed that satellite imagery can provide important information for mining environment and resolve controversies about future management directions [2-5].

There is a serious risk of chemical extraction from Weathering Crust Elutiondeposited Rare Earth Ores that can make a major environmental damage in this area. Currently, the new technology has stepped into the third stage. In the first stage, the rare earth was separated using sodium chloride with oxalic acid as the precipitant. This process resulted in large amounts of wastewater contained high sodium chloride, which may pollute the surrounding soil and vegetation. Additionally, the residue of sodium chloride remained in the tailings would lead to soil salinization and affect the vegetation growth; In the second stage, sodium chloride was replaced by the ammonium sulfate as leaching solvent, which can reduce the soil pollution. However, the large-scale exploitation and depositing of ore body would result in the land destruction, water and soil loss[6]; In the third stage, the liquid was injected to 
dissolve ore body directly without exploitation, and then rare earth elements were separated. However, this process had a risk of landslide [7-9].

Gannan is the mainly rare earth mining area in China. The high profit of the rare earth increases illegal mining in this area, which brings high environmental cost. As the large cover area of Weathering Crust Elution-deposited Rare Earth Ore, it is quite difficult to monitor and manage the whole area using traditional monitoring way based on field survey. The remote sensing technology has the capacity to acquire large area surface information and complete dynamic mining monitoring. Therefore, this study is aim to monitor rare earth mining in Gannan area using SPOT imagery, and acquire the information of dynamic exploitation process, we using manual interpretation method to discriminate the destroyed area. with the SPOT5 imagery, and filed surveying to confirm the result.

\section{The Study Area}

Gannan area of South China is rich in the rare earth sources. This study area was located in the west of Gannan (Figure1). The climate in this area is the tropical to

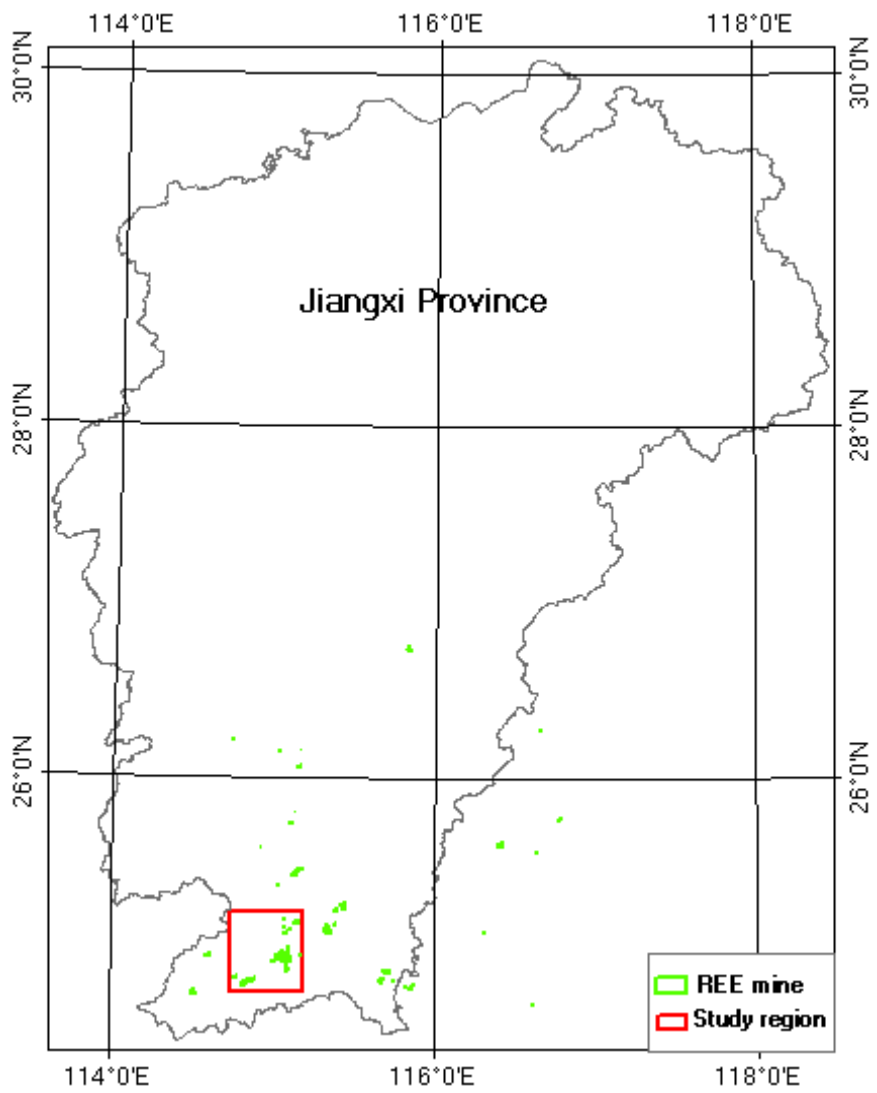

Fig. 1. The location of the study area in Gannan, China 
subtropical. The wet and humid climate makes the flourishing plants, which is the source of the organic acid. It simulates the chemical weathering and formation of surface weathering crust. The rare earth is mainly from the weathering crust, even around 10 times higher than that from the base rock. This area is in the hilly country with elevation less than $550 \mathrm{~m}$. The topographic relief difference is $250 \mathrm{~m}-260 \mathrm{~m}$. Gannan as the firstly mining area of rare earth exploitation has killed and polluted large area. Currently, there are dozens of active mining site in this area. The serious environmental issues are land degradation with vegetation removal and soil pollution.

\section{Data and Method}

In this study, the human interpretation was conducted to extract mining information from high resolution imagery, and then the data from field trip was used for accuracy assessment.

\subsection{Data}

Multi-spectral SPOT data with $10 \mathrm{~m}$ resolution was used in this study, which acquired at 4th December 2010 with the dimap format. The ancillary data for image classification was Landsat/ETM data with $14.25 \mathrm{~m}$ resolution and ASTER GRID DEM with 30m resolution (http://gdex.cr.usgs.gov/gdex/).

\subsection{Ortho-rectification}

As the landform of hilly country in this area, the mining site mostly located on the top of the hill. In order to target mining site accurately, the ortho-rectification of the imagery is necessary. Firstly, the band was composited by 412 for image interpretation. Furthermore, 21 ground control points were selected from ETM imagery. The ortho-rectification of SPOT5 imagery was conducted using bilinear interpolation resampling method based on the ERDAS's SPOT 5 orbital-pushbroom model. The average RMS error was below 1 pixel following ortho-rectification. As shown in the Figure 2, the SPOT 5 imagery covered the study area after ortho-rectification (Figure 2). 


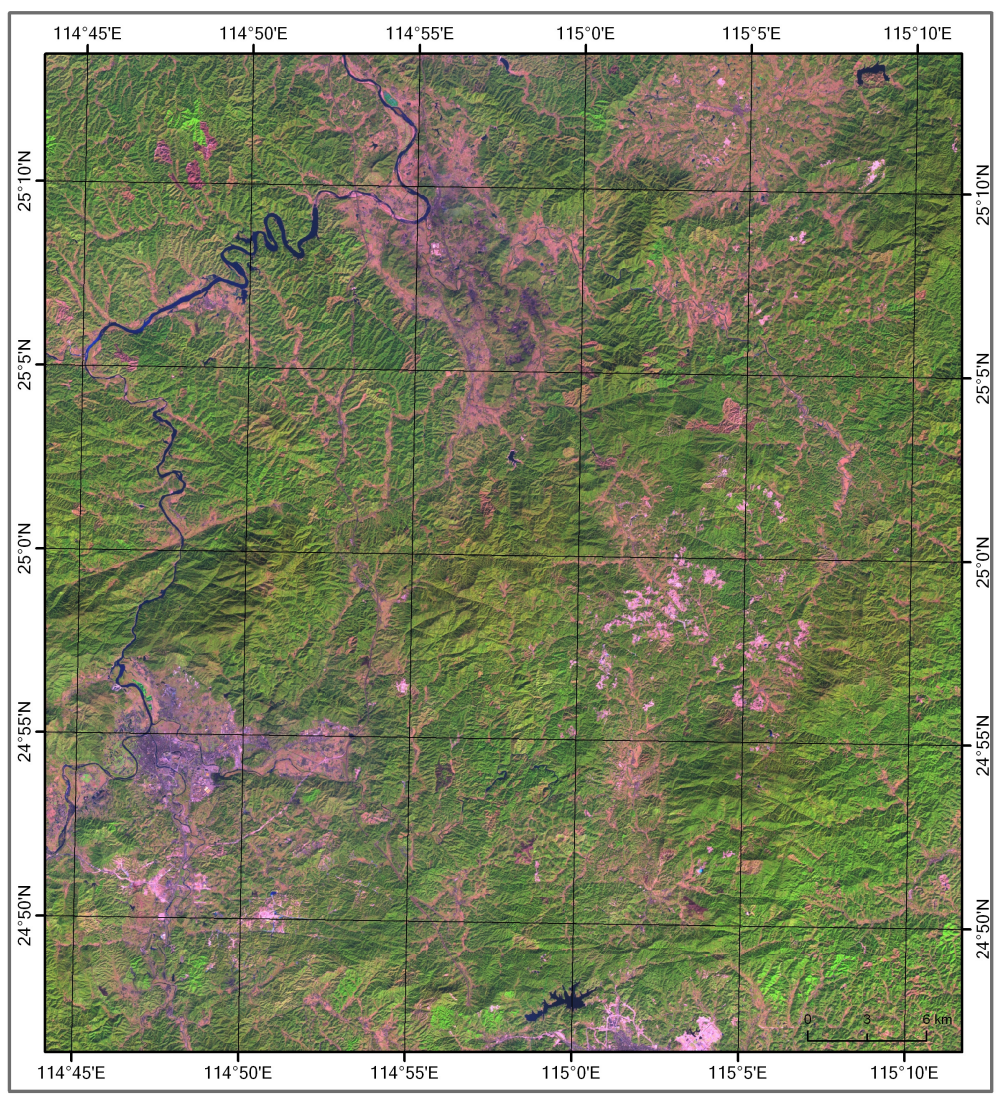

Fig. 2. The ortho-recitified SPOT5 imagery with 412 RGB combination covered study area

\subsection{Image Interpretation Thumb}

No matter traditional or advanced extraction technology, both ways would result in the land destruction or landslide, which would perform as the bare ground in the imagery. Given to the hilly country area, the land cover information with disturbed or destroyed by mining was easily identified in human interpretation, as shown in the Figure3. The target object was digitized and drew under ArcGIS10.0 from human interpretation. Each object was labeled by different land cover type. Topologic checking was conducted to confirm the classification result. The smallest size of object was 6 pixels by 6 pixels. 


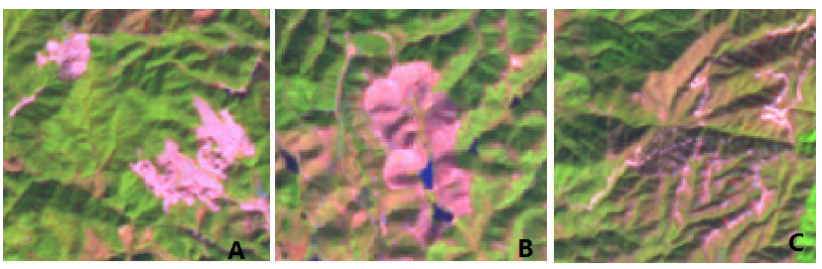

Fig. 3. The target object with pink color visualized in the imagery. A: The hill body was stripped; B. The vegetation was removed; C The plants in the gully was destroyed.

\section{$4 \quad$ Results and Analysis}

The amount of patches in total was 524 with the area of $60.97 \mathrm{~km} 2$, which accounted for $3.03 \%$ in the study area. The largest patch size of destroyed area was $8.1 \mathrm{~km} 2$. The average patch size of destroyed area was around $1.30 \mathrm{~km} 2$. There were 513

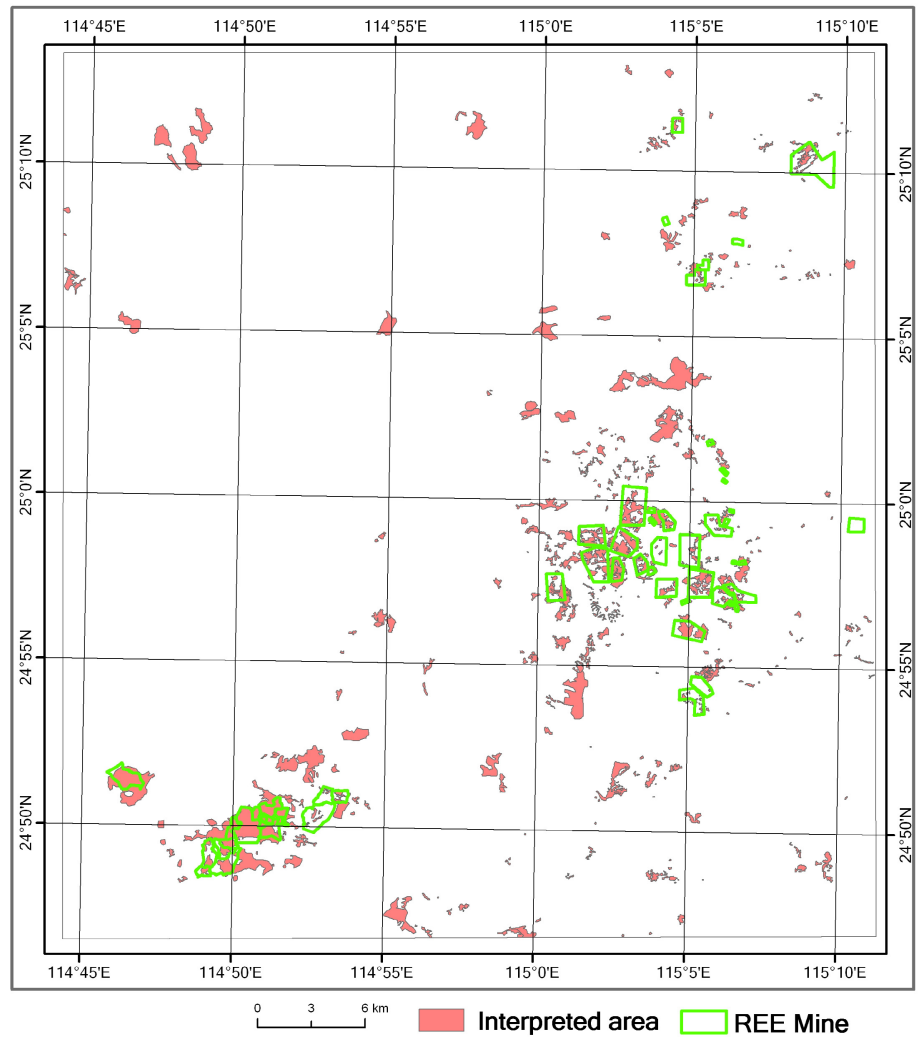

Fig. 4. The classified results by human interpretation. (REE mine: rare earth elements). 


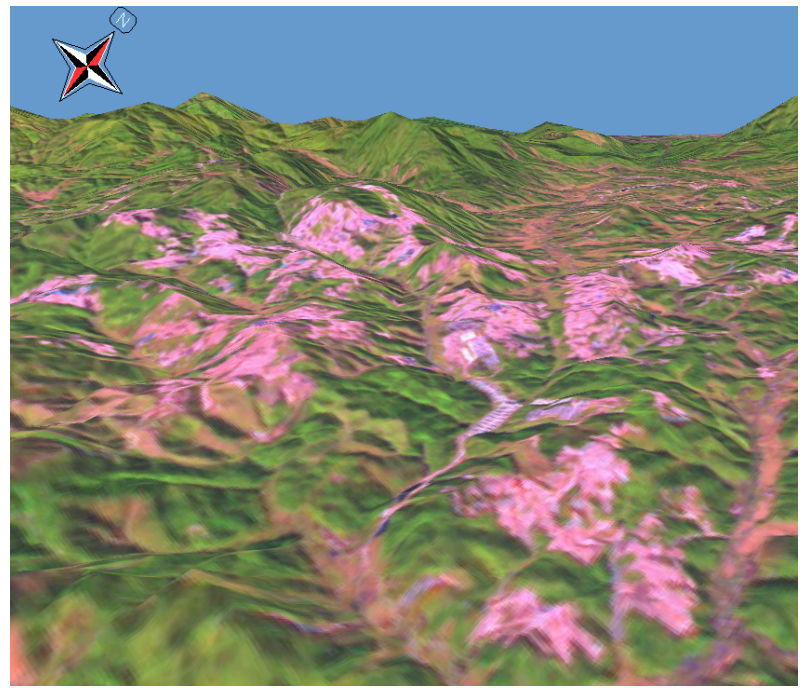

Fig. 5. 3D visualization in ArcGlobe

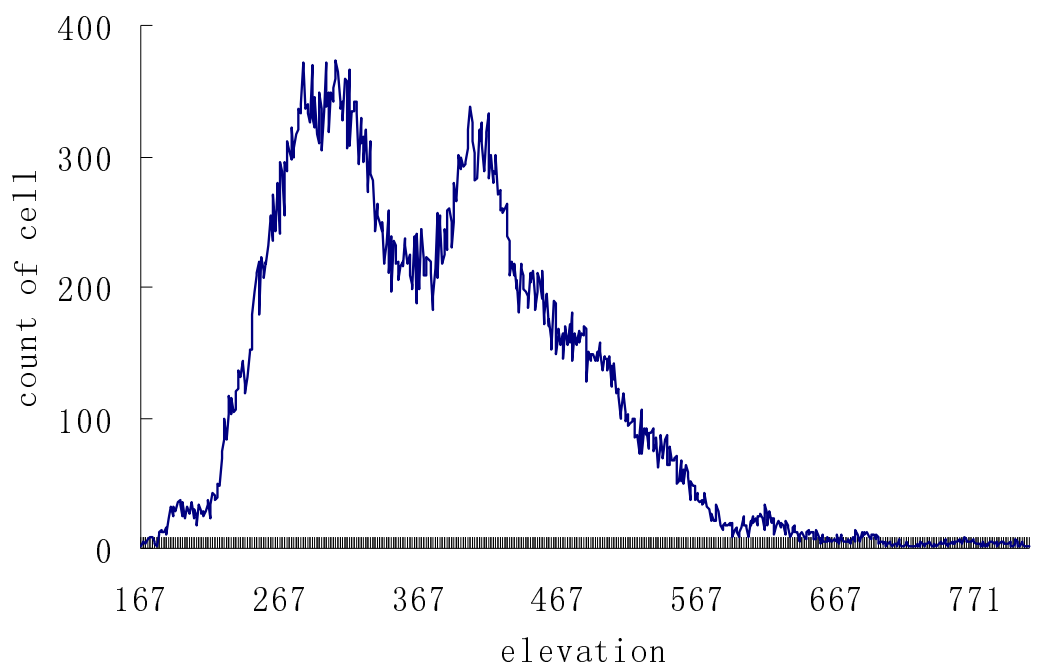

Fig. 6. The elevation distribution in mining area 
patches of destroyed area less than $1 \mathrm{~km} 2$ distributed in the southwest of the study area. As shown in the Figure 4, the mining actives taken place at the east and south of this area, which corresponded to the classified results from the interpretation. The patches which represented the destroyed land cover can match the mining activities and mining lease.

The 3D analysis was conducted through ArcGlobe using SPOT and DEM data (Figure 5). Most REE mining activities mainly occurred on the top of the hill, which can be easily visualized from $3 \mathrm{D}$ imagery.

In order to analysis the landform of mining area, the interpreted polygons were converted to Grid by $30 \mathrm{~m}$ resolution. Through overlaid with ASTERDEM, it was found that the elevation of the active mining area was between $300 \mathrm{~m}$ to $500 \mathrm{~m}$, and the slope of that area was between 10 degree to 20 degree.

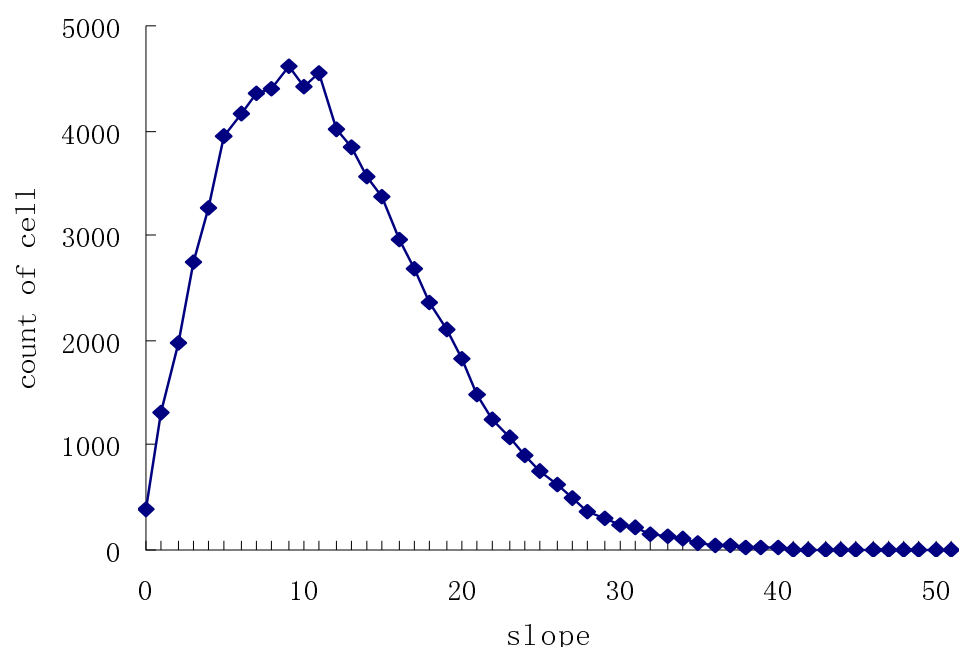

Fig. 7. The slope distribution in mining area

\section{$5 \quad$ Field Survey}

The field trip in the Quannan, Dingnan and Longnan district of Gannan area were taken on Nov. 2012 for the accuracy assessment. The photos collected from this trip showed that landform in this mining area was totally changed by exploitation and digging. As shown in the Figure8, the vegetation was removed and destroyed in the mining area, and the serious water and soil loss occurred in this area. 


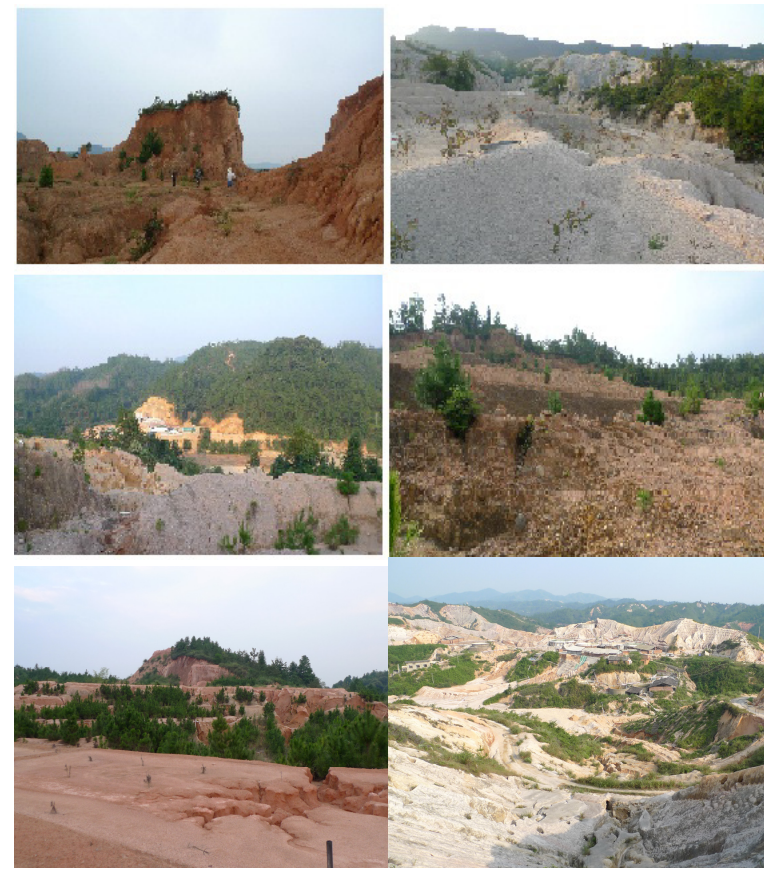

Fig. 8. The photos taken in Gannan mining area

\section{Conclusion}

Remote sensing has been a necessary and advanced technology in mining environmental monitoring, which can provide accurate, effective and comprehensive information for target object. The dynamic and update information from remote sensing technology can give a data support for Government and mining company to organize the environment rules and plan. Furthermore, high resolution imagery was required to acquire more detail information in mining area. Additionally, the small and disperse mining area should be integrated, which can be monitored and managed more easily and effectively.

\section{References}

1. Chen, H., Xu, X., Liu, Y.: Review of Researches on Remote Sensing Monitoring and Impact on Environment of Land Use/Cover Change. Meteorological Science and Technology 33(4), 289-294 (2005)

2. Bian, Z., Zhang, Y.: Land Use Changes in Xuzhou Coal Mining Area. Acta Geographica Sinica 61(4), 349-358 (2006)

3. Chen, L., Guo, D., Hu, Z., et al.: A Study on Remote Sensing Monitoring Land Use Change and Reclamation Measures of Subsided Land in Xuzhou Coal Mining Area. Progress In Geography 23(2), 10-15 (2004) 
4. Chen, H.-L., Chen, G., Guo, J.-Z.: The Application of Landsat TM for Ecological Environmental Monitoring in Mining Area. Remote Sensing Information (1), 31-34 (2004)

5. Wang, P., Liu, S.-F.: The detection of REE mine exploitation site change based on multitemporal remote sensing images. Remote Sensing for Land \& Resources 2, 65-68 (2007)

6. Lan, R.: The environmental problem and advice on Ion-adsorption Type Rare Earths Mineral. Truth Seeking (5), 174-175 (2004)

7. Chi, R.-A., Tian, J., Luo, X.-P.: The basic research on the weathered crust elution-deposited rare earth ores. Nonferrous Metals Science and Engineering 3(4), 1-13 (2012)

8. Liu, Y.: Water and soil loss and Treatment methods after Improved Rare Earth continuous mining technology. Water Resources Development Research 2(2), 30-32 (2002)

9. Zhao, J., Tang, X.-Z., Wu, C.: Status Quo of Mining and Recovering Technologies for Ionabsorbed Rare Earth Deposits in China. Yunnan Metallurgy 30(1), 11-14 (2001) 